\title{
Radial basis function neural networks in prediction and modeling of diesel engine emissions operated for biodiesel blends under varying operating conditions
}

\author{
R. Manjunatha ${ }^{1 *}$, P. Badari Narayana ${ }^{2}$, K. Hemachandra Reddy ${ }^{3}$ andK. Vijaya Kumar Reddy ${ }^{4}$ \\ ${ }^{1}$ Irrigation Department, GBC Division Guntakal-515801 AP, India. \\ ${ }^{2}$ Cybermotion Technologies Pvt. Ltd., Hyderabad-500034 AP, India. \\ ${ }^{3}$ Director-Academic and Planning, JNT University-Anantapur-515001 AP, India. \\ ${ }^{4}$ Deparment of Mechanical Engineering, JNTU College of Engg. Hyderabad-500072 AP, India. \\ manju.biodsl@gmail.com ${ }^{1 *}$, badari.p@gmail.com ${ }^{2}$, konireddy@gmail.com ${ }^{3}$,kvijayakumarreddy@gmail.com ${ }^{4}$
}

\begin{abstract}
Biofuels are environmental friendly and their utilization addresses global concerns about containment of carbon emissions. Biodiesel certification involves analysing these emissions for various biodiesel blends in order to certify \& recommend the new fuel to transport sector. Conducting the experiments for emission analysis is tedious and time consuming. Modeling the emissions operated for various biodiesel blends will help biodiesel manufacturers and certification authorities in analysing the possible pollutant levels. Artificial neural networks (ANN) can be used in modelling and prediction of biodiesel emissions operated under varying operating conditions. The objective of this research work is to design a neuro computing model to analyze the complex process of diesel engine emissions formation and estimate exhaust emissions operated with biodiesels under variable operating conditions. Experimental data of a single cylinder four stroke diesel engine run with various biodiesel blends has been used for training the network. During testing phase, emissions are predicted for new biodiesel \& its blends. ANN developed is based on radial basis function neural networks (RBFNN). Predictive ability of this neural network is analysed using statistical analysis. The developed model has shown improved coefficient of determination (CoD) values of 0.99, 0.99, 0.96, 0.98 and 0.95 for $\mathrm{NO}_{\mathrm{x}}, \mathrm{HC}, \mathrm{CO}, \mathrm{CO}_{2}$ and smoke emissions respectively. These results indicate that radial basis function neural networks are superior to the traditional back propagation algorithm based multi layer neural networks in terms of accuracy and efficiency performance. In this work, prediction \& emission modelling of diesel engine operated with different biodiesel blends under varying operating conditions is successfully demonstrated. Hence, RBFNN can be used as a powerful virtual sensing technology tool for prediction \& modelling of biodiesel emissions.
\end{abstract}

Keywords:ANN, biodiesel, radial basis function, coefficient of determination, MAPE.

\section{INTRODUCTION}

India's energy security is dependent on alternative fuels that are developed based on indigenously produced renewable feedstock (Krzy zaket al., 1996). Biodiesels derived from non-edible oils have been considered as a long term substitute for petroleum diesel fuel, due to similarities in properties and operating characteristics of diesel engines. Biodiesels can be domestically produced, biodegradable and relative to conventional diesel fuel, their combustion products have significantly reduced levels of $\mathrm{CO}, \mathrm{CO}_{2}, \mathrm{HC}$ and Smoke. Objective of this work is to evaluate the diesel engine emissions of a diesel engine when operated with biodiesels \& blends. Artificial Neural Networks have been used for diesel engine performance and emission analysis by researchers and is the choice of technology as it would simulate the engine $\&$ its operation to produce exhaust emissions with better accuracies. The predictive ability of an ANN results from training on experimental data and testing on independent data. Effective Pre-Processing and Post-Processing along with goodness of fit analysis is part of the neural network processing. In this paper, applicability of radial basis function neural networks (RBFNN) approach for modeling the biodiesel emissions is investigated. Many of the techniques of ANN cited in the literature (Himabindu \& Mahalakshmi, 2011)use the MLP (Multi Layer Perception) based ANN that is coupled with the error back propagation algorithm for model parameter estimation. RBFNN method differs from widely used multilayer perceptron modeling approach in which the non-linearity of the model is embedded only in the hidden layer of the network (Amherst, 1999). RBFNN offers a faster prediction than a conventional simulation program or mathematical modeling technique.

Experimental investigation

Fig. 1. Test rig setup

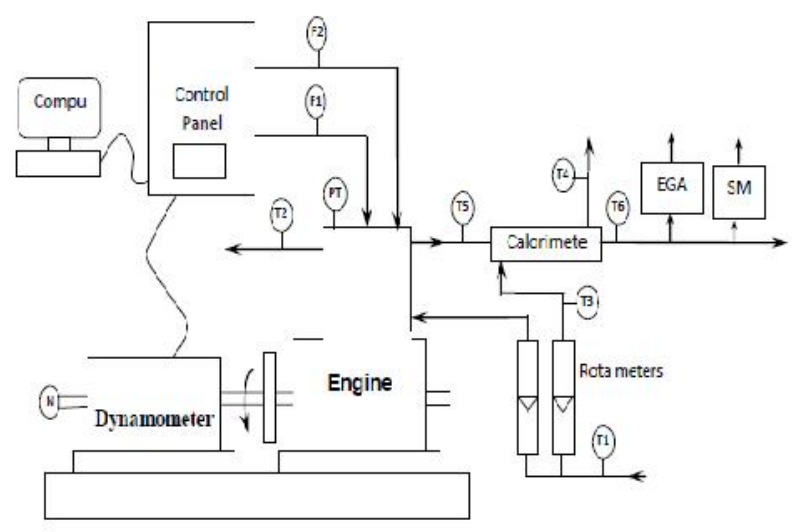

Research article

(CIndian Society for Education and Environment (iSee)
"Biodiesel blends"

http://www.indjst.org
Manjunatha et al. Indian J.Sci.Technol. 
Table 1. Properties of biodiesels

\begin{tabular}{|l|l|l|l|}
\hline Oil & $\begin{array}{l}\text { Density } \\
(\mathrm{gm} / \mathrm{cc})\end{array}$ & $\begin{array}{l}\text { Kinematic } \\
\text { Viscosity(cst) }\end{array}$ & $\begin{array}{l}\text { biodiesel } \\
\text { percentage }\end{array}$ \\
\hline Castor & 0.956 & 52 & $25,50,75,100$ \\
\hline Linseed & 0.929 & 22.2 & $25,50,75,100$ \\
\hline Palm Stearin & 0.918 & 39.6 & $25,50,75,100$ \\
\hline Mahua & 0.917 & 0.917 & $25,50,75,100$ \\
\hline Neem & 0.919 & 0.919 & $25,50,75,100$ \\
\hline
\end{tabular}

Extraction of liquid biodiesel fuel from the non-edible oils is done by mechanical crushers known as oil expellers. Then the oil is treated for transesterification, purification and micro-emulsification to reduce fuel viscosity such that biodiesel would be suitable to run in a diesel engine. A schematic diagram of the experimental setup is shown in Fig.1.Data collected from this experimental work consists of: density, kinematic viscosity and blend percentage as static properties of the selected biodiesels (Table 1) for running the diesel engine and brake power, exhaust gas Temperature (EGT) $\left(\mathrm{T} 5^{0} \mathrm{C}\right)$ as the dynamic operating characteristics representing the engine's performance.

A four gas analyser along with smoke meter is used for measuring the exhaust emissions - $\mathrm{CO}, \mathrm{CO}_{2}, \mathrm{HC}$ (unburnt hydrocarbons), NOx and Smoke. The tests were conducted with variable loads $(0,1,2,3,4,5.2 \mathrm{KW})$ at constant engine speeds of $1500 \mathrm{rpm}$ at constant injection timing of $55^{\circ}$ before top dead centre (duration $0.01 \mathrm{sec}$ ) and at constant injection pressure (210 bar) for the biodiesel blends of $25 \%, 50 \%, 75 \%$ and $100 \%$. The experimental results are tabulated and data obtained is used for modeling the emissions.

Neural network design \& development

The combustion analysis and emission formation is inherently non-linear where the conventional mathematical models fail to give solutions. Artificial Neural Networks is a real time diagnostic, modeling, control and optimization tool that has the ability to capture non-linearties of system variables. ANNs extract the required information directly from the data because of their unique learning capability. They are capable of learning from nonlinear data of a complex problem and can predict the desired values with high accuracies. Radial Basis Neural Networks is a special type of artificial neural network that has been successfully applied in many areas like function-approximation and predictions [2]. In this work, a radial basis neural network is developed for emission modeling of biodiesels when operated in a diesel engine under varying operating conditions.

Data preparation and pre-processing:Data preparation and organization is an important step in neural network experiments. During the current study, the entire biodiesel engine test data records are arranged as inputoutput (target) mapping parameters. 25\% of the samples are employed for testing phase and the remaining is used for training. Testing samples consists of new biodiesel operating data, whose inputs alone (which are unseen by the network till now) are supplied during the testing or application phase. ANN methods require data to be preprocessed before being used in the prediction process. Generally, the pre-processing step includes omitting outliers, assessment of the missing data, data smoothing, etc (Azadeh et al., 2011). Activation functions such as sigmoid, Gaussian function demand the data to be in limited range of values i.e. all the values are to be in between $[0,1]$. This is known is data normalization and is performed by dividing each data record with a selected scaling factor (Hertz et al., 1991).

Radial basis function neural networks: Artificial Neural network is an application that alters certain variables in response to a set of corresponding input and output patterns. Beginning with an initial set of internal values, the network modifies these quantities in order to find a position of "best fit," thereby generating from the input patterns their expected results. Multi-Layer perceptron models have been used in solving complex problems where large amount of data is involved. The ability of these networks to generalize relationships between inputs and outputs is a key to their effectiveness. Back Propagation based Neural Networks have been effective at providing higher accuracy levels for predicting biodiesel emissions for a new fuel and its blend (Sola \&Sevilla 1997). For all these related algorithms, the basic method of learning consists of calculating an "error term" dependent on the difference between the predicted and actual outputs, adjusting the weights between the neurons in order to lower that term, and propagating the effects of the error term through previous layers of weights. This process is repeated until the level of difference between obtained and predicted outputs is within an acceptable boundary(Himabindu \& Mahalakshmi, 2011). The basic model of multi-layer neural networks utilizes either sigmoid or threshold neurons.

Radial basis function methods became a popular technique in the mid1980s for performing exact interpolation of a set of data points in a high-dimensional space (Powell, 1987). Learning is equivalent to finding a multidimensional function that provides a best fit to the training data, with the criterion for "best fit" being measured in some statistical sense. Radial basis function (RBF) networks typically have three layers- an input layer, a hidden layer with a non-linear RBF activation function and a linear output layer. The RBF network consists of one hidden layer of basis functions, or neurons. At the input of each neuron, the distance between the neuron centre and the input vector is calculated. The output of the neuron is then formed by applying the basis function to this distance.

Various Radial Basis functions have been tested as activation functions for RBF Networks (Himabindu \& Mahalakshmi, 2011). Radial Basis Function Neural Network uses following function types. The task is to
Research article

CIndian Society for Education and Environment (iSee)
"Biodiesel blends" http://www.indjst.org
Manjunatha et al. Indian J.Sci.Technol 
determine a function Sin linear space such that $S\left(x_{i}\right)=t_{i}$; $\mathrm{i}=1, \ldots \mathrm{n}$. The interpolation Function is a linear combination of basis functions.

$$
\underset{i=1}{\mathrm{~S}(\mathrm{x})}=\sum \mathrm{W}_{\mathrm{i}} \mathrm{V}_{\mathrm{i}}
$$

and the basis function of the form is given by $V_{i}(\mathrm{x})=\Phi\left(\left\|\left(\mathrm{x}-\mathrm{x}_{\mathrm{i}}\right)\right\|\right)$

Where $\Phi$ is mapping $\mathrm{R}+\rightarrow \mathrm{R}$ and the norm is Euclidean distance. Following have been considered as radial basis functions.

$$
\begin{aligned}
& \text { Thin Plate Spline Function } \\
& \Phi(r)=r^{2} \log (r) \\
& \text { The Gaussian Function } \\
& \Phi(r)=e^{-(r 2 / \beta 2)} \\
& \text { The Multiquadric function } \\
& \Phi(r)=\left(r^{2}+\beta^{2}\right)^{1 / 2} \\
& \text { The Inverse Multiquadric Function } \\
& \Phi(r)=1 /\left(r^{2}+\beta^{2}\right)^{1 / 2}
\end{aligned}
$$

Where $r$ is the non-negative number and is the distance from centre $C, \beta$ is the width of radial basis functions.

Selected architecture:To predict the exhaust emissions of diesel engine operated with biodiesels under varying operating conditions, radial basis function neural network is developed. The neural network consisted of one hidden layer based on Gaussian radial basis function. Input and output layers are linear and sigmoidal. 5-18-5 is derived to be a better architecture after conducting various trials by changing the neurons in the hidden layer. There found to be 18 neurons in the most optimum neural network in terms of performance.

Table 2. Engine specifications

\begin{tabular}{|l|l|}
\hline Parameter & Specification \\
\hline No. of Cylinders & 1 (4 Stroke) \\
\hline Cooling System & Water Cooled \\
\hline Bore & $87.5 \mathrm{~mm}$ \\
\hline Stroke & $110 \mathrm{~mm}$ \\
\hline Rated Power & $5.2 \mathrm{KW} / 7 \mathrm{HP}$ \\
\hline Rated Speed & $1500 \mathrm{rpm}$ \\
\hline Dynamo Meter Arm Length & $185 \mathrm{~mm}$ \\
\hline Dynamo Meter Type & Eddy Current \\
\hline Compression Ratio & $17.5: 1$ \\
\hline
\end{tabular}

ANN Parameters:The optimal selection of ANN training and architectural parameters is largely problem dependent Table.2 shows the selected parameters after various trial and error runs. Speed convergence, accuracy, and performance parameters (given in III D) are the points of interest in designing a most optimum neural network. Errors during learning and testing stages are described by root mean square error (RMSE), which is computed as below (Fig 2$)$

\section{RMSE $=\left(\sum_{j}\left|\left(t_{j}-o_{j}\right)\right|^{2}\right)^{1 / 2} \ldots(2)$}

Where $t_{j}$ is the actual target value supplied during supervised learning and $o_{j}$ is the neural network output value.
Vol. 5 No.3 (Mar 2012)

ISSN: 0974- 6846

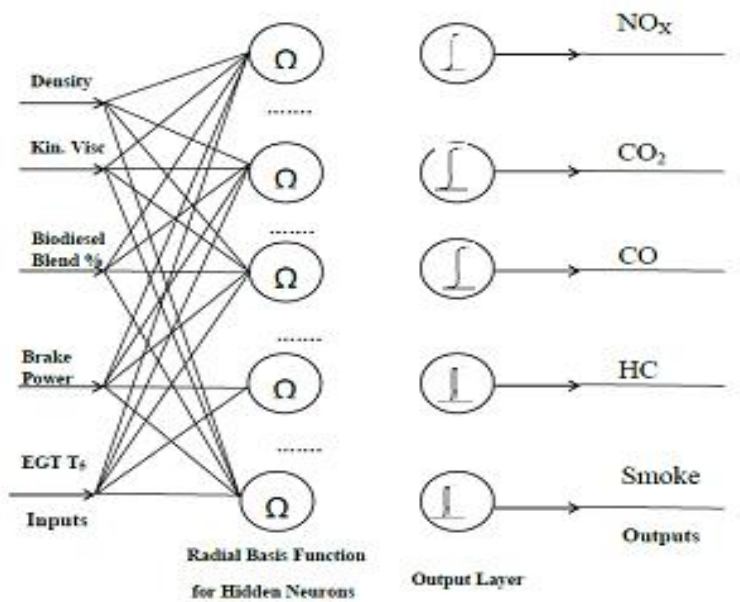

Neural network is run for 0.001 as network performance goal and better results are obtained after running 10000 training cycles for the selected RBFNN architecture of 5-18-5. Learning rate of 0.6 and momentum factor of 0.9 or 1.0 is found be effective neural network training parameters; it is observed that momentum factor 0.9 gives equal predictions some times during training \& testing. Care should be taken in fixing these parameters as we need to select them based on experience. Convergence speeds depend mainly on complexity of the data, chosen number of hidden layers, hidden neurons and affected by activation function and learning rate.

Table 3.ANN Test Results

\begin{tabular}{|l|l|l|l|}
\hline \multicolumn{1}{|c|}{ Algorithm } & $\begin{array}{c}\text { Network } \\
\text { minimum error } \\
\text { achieved }\end{array}$ & Architecture & $\begin{array}{c}\text { Raining } \\
\text { Cycles }\end{array}$ \\
\hline Back Propagation & 0.005 & $5-18-12-9-5$ & 100000 \\
\hline $\begin{array}{l}\text { RadialBasis } \\
\text { Function Neural } \\
\text { Network }\end{array}$ & 0.003 & $5-18-5$ & 10000 \\
\hline
\end{tabular}

Evaluating ANN results: Verification and validation should always form a significant portion of any modeling \& simulation exercise that develops predictive models. Hence, the predicted new biodiesel blend's emissions are compared to the actual experimental values using goodness-of-fit analysis. The results are shown in Table 3. Performance evaluation parameters -Coefficient of Determination (CoD) and Mean Average Percentage error (MAPE), are calculated for both the back propagation based ANN and RBFNN (Table 4).

$$
\operatorname{CoD}=1-\left(\sum_{j=1}^{n}\left(t_{j}-O_{j}\right)^{2}\right)
$$

$$
\text { MAPE }=((0-t) / t) * 100
$$

Actual and predicted emission values for $100 \%$ biodiesel blend under varying operating loads are 
Represented in Fig. 3 to 7. At full load, $\mathrm{NO}_{\mathrm{x}}$ and $\mathrm{CO}_{2}$ show ' $S$ ' trend with change in percentage of biodiesel blends. The hydrocarbon emission revealed a decreasing trend with high blends of bio diesel Fig 8-12 shows the effect of biodiesel blend over smoke, which is increasing with biodiesel content. Complexity of burning process, unidentified experimental noise would have resulted in lower value of $\mathrm{CoD}$ and higher value of MAPE for predicting the smoke. These predictions show that, there exists a strong correlation between inputs vs. Outputs i.e. exhausts emissions vs. selected influencing combustion parameters, which is captured by the developed neural network.

\begin{tabular}{|c|c|c|c|c|}
\hline \multirow[t]{2}{*}{$\begin{array}{l}\text { Emission } \\
\text { Parameter }\end{array}$} & \multicolumn{2}{|c|}{$\begin{array}{l}\text { Coefficient of } \\
\text { Determination } \\
\text { (CoD) }\end{array}$} & \multicolumn{2}{|c|}{$\begin{array}{c}\text { Average of Mean } \\
\text { Average Percentage } \\
\text { Error (MAPE) }\end{array}$} \\
\hline & BPN & RBFNN & BPN & RBFNN \\
\hline NOx & 0.9921 & 0.9942 & 4.038 & 3.34 \\
\hline $\mathrm{HC}$ & 0.9844 & 0.9997 & 13.381 & 3.26 \\
\hline $\mathrm{CO}$ & 0.9314 & 0.9664 & 14.67 & 10 \\
\hline $\mathrm{CO}_{2}$ & 0.9864 & 0.9816 & 6.09 & 4.9 \\
\hline Smoke & 0.9355 & 0.9504 & 20.54 & 12 \\
\hline
\end{tabular}

\section{Conclusions}

ANNs have better learning ability, generalization, parallel processing, and error endurance attributes that lead to perfect solutions in applications where we need to model the nonlinear mapping of complex data. A multilayer ANN is established and the number of neurons used in the hidden layers is determined by experience and performance of the derived architecture is substantiated by statistical techniques. Input response sensitivity verification by including input parameters such as flash point, fire point, cetane number etc., has been tried in order to find out their influence. Finally, effect of given fuel properties (density, kinematic viscosity along with biodiesel blend percentage) for various biodiesel blends and the operating parameters brake power and EGT are found to be better influencing factors to produce exhaust emissions. Selection of searching algorithm for ANN depends on the complexity of data, number of input parameters, output parameters, available computing power and the speed of learning. The designed model of RBFNN has given quick speed of convergence and improved accuracy, Result of comparing the RBF implementation against the traditional BPN based neural network shows the superiority of the radial basis method for predictive ability. MAPE is a suitable metric to evaluate the performance of neural networks. In this study, most of the predicted emissions of new biodiesel (testing data samples) have shown MAPE averages of less than $10 \%$, Coefficient of determination nearer to unity indicates that the model is successful in predicting and modeling the exhaust emissions for a new biodiesel and its blends. The focus of this study was the development of neural network models for diesel engine emission modelling for various biodiesel blends. With the results obtained, it can be claimed that ANN to model exhaust emissions, is a powerful virtual sensing tool for the analysis of combustion phenomenon of diesel engine operated with biodiesel blends.

Fig. 3. Brake Power Vs. NOx Emission

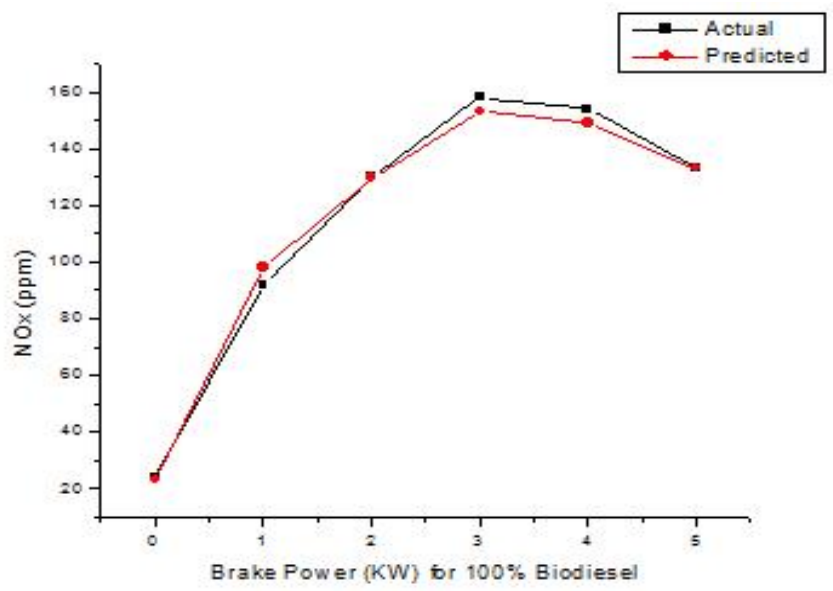

Fig.4. Brake Power Vs. HC Emission

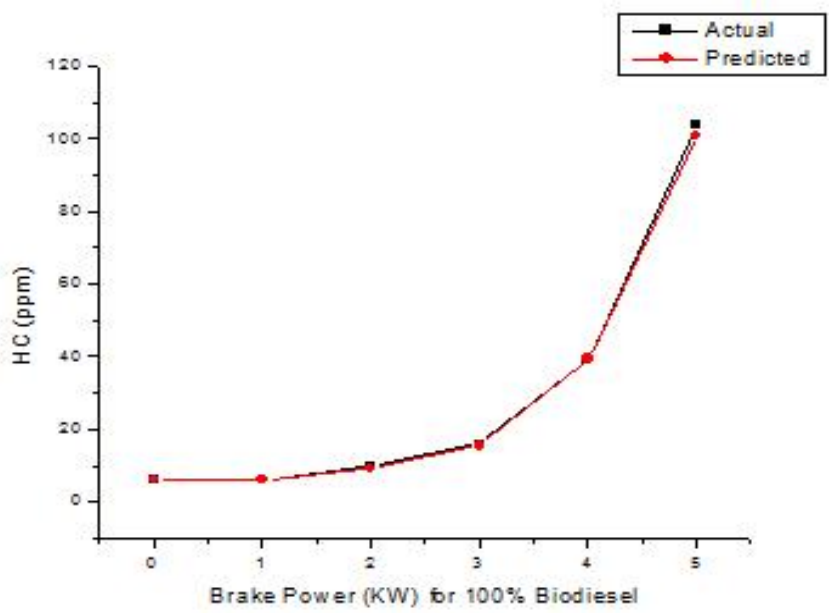

Fig. 5. Brake Power Vs. CO Emission

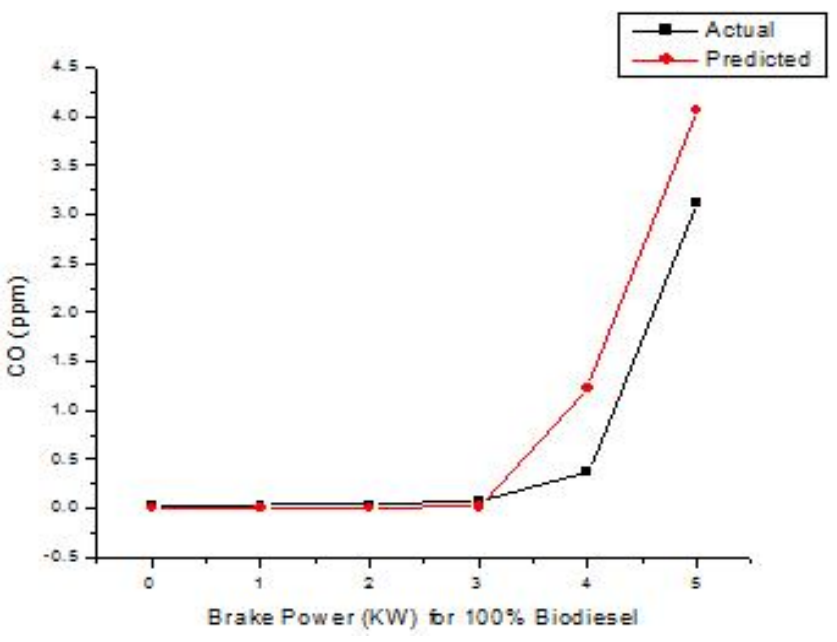

Manjunatha et al. Indian J.Sci.Technol. 
Fig. 6. Brake Power Vs. $\mathrm{CO}_{2}$ Emission

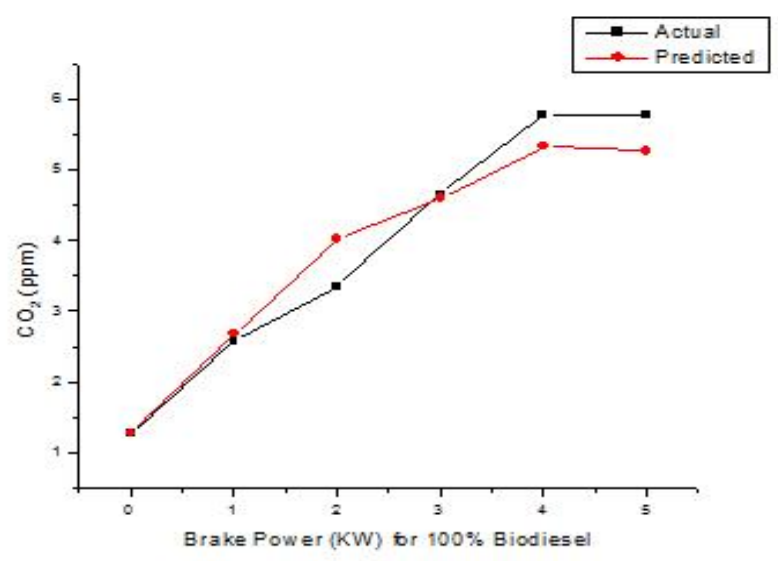

Fig. 7. Brake Power Vs. Smoke Emission

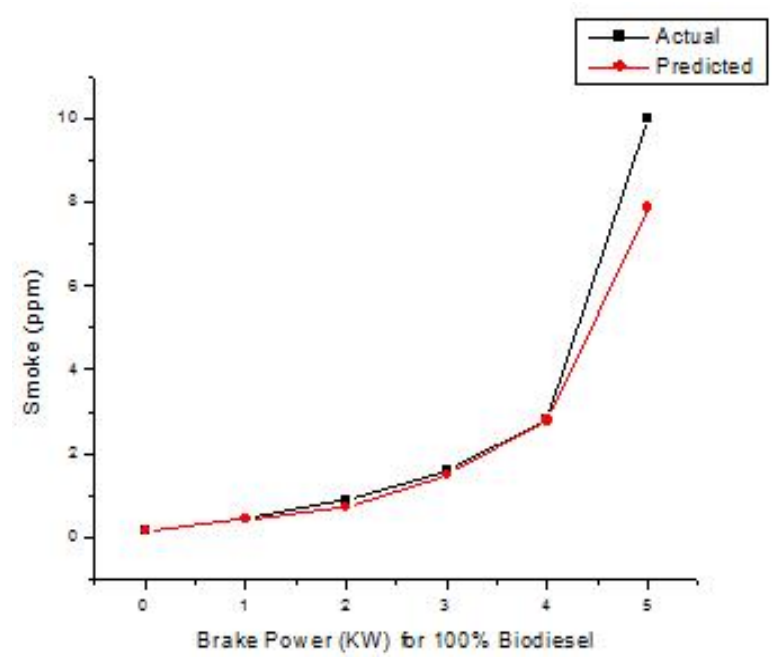

Fig. 8. Blend Percentage Vs. NOx Emission

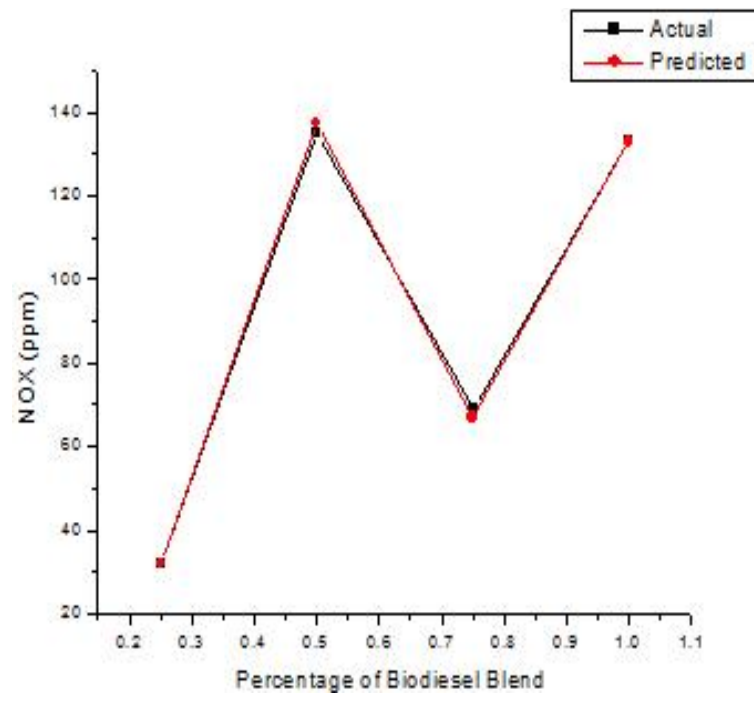

Vol. 5 No.3 (Mar 2012)

ISSN: 0974- 6846
Fig. 9. Blend Percentage Vs. HC Emission

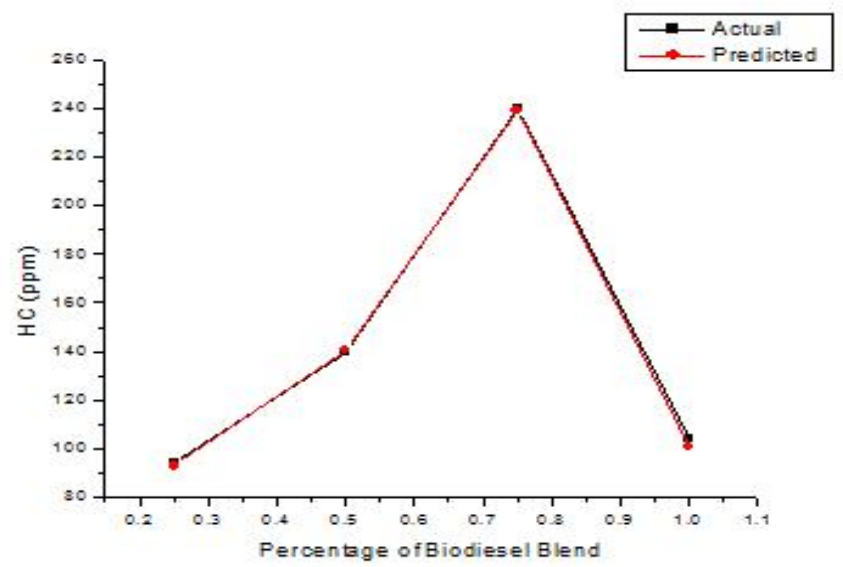

Fig 10. Blend Percentage Vs. CO Emission

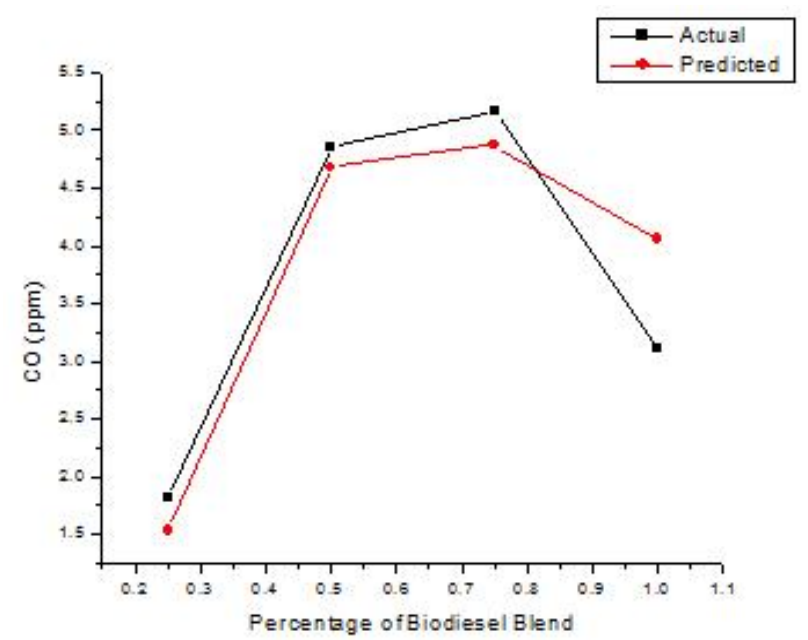

Fig. 11. Blend Percentage Vs. $\mathrm{CO}_{2}$ Emission

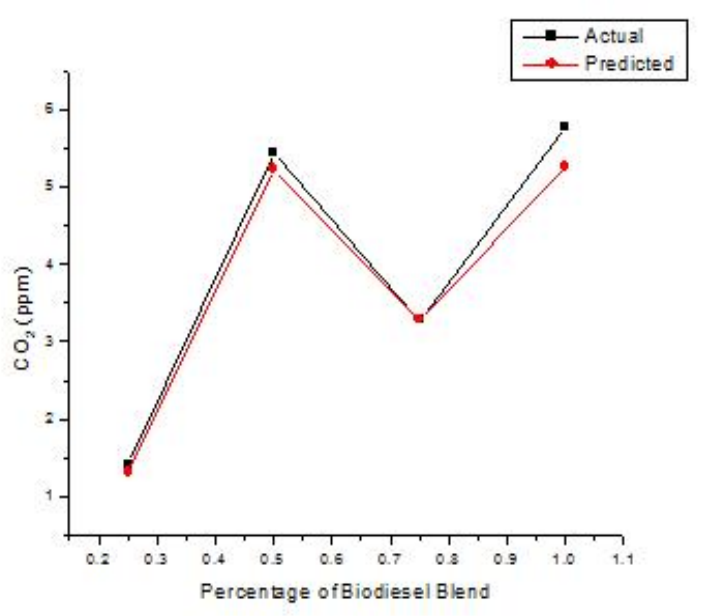


Fig. 12. Blend Percentage Vs. Smoke Emission

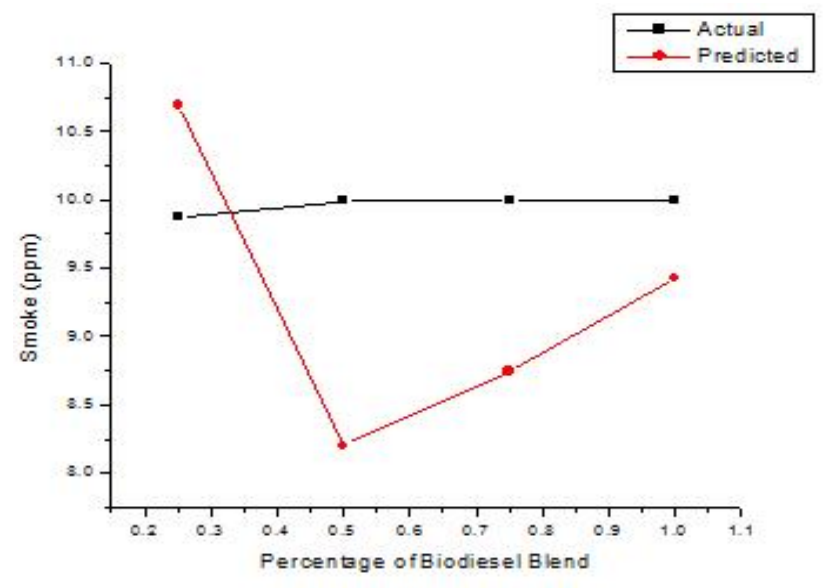

References

1. Amherst MA (1999) CMPSCI Tech. Rep. pp: 99-102.

2. Azadeh $A$, Sheikhalishahi $M$, Tabesh $M$ and Negahban A (2011) The effects of pre-processing methods on forecasting improvement of artificial neural networks. Aus. J. Basic .Appl. Sci. 5(6), 570580 ,

3. Biodiesel policies for rural development in India (2008) Field Survey Report, submitted to German 27th May.

4. Hertz J Krogh A and Palmer RG (1991) Introduction to the theory of neural computation. Addison-Wesley Publ. Co, Redwood City, NJ.

5. Himabindu M and Mahalakshmi NV (2011) Effect of dual fuel homogenous charge diesel combustion for simultaneous reduction of NOx and smoke- an experimental study. Indian J.Sci. Technol . 4 (6), 681687.

6. Krzy zak A, Linder $T$ and Lugosi G (1996) Nonparametric estimation and classification using radial basis functions, IEEE Trans.NeuralNetworks. 7, 475-487.

7. Rajasekharan S and Vijaya Lakshmi Pai GA (1997) Neural networks. In: Fuzzy Logic, \& Genetic Algorithms, Program. @ 2003 by Printice-Hall of India Pvt Ltd, New Delhi.

8. Sola J and Sevilla J (1997) Importance of data normalization for the application of neural networks to complex industrial problems, IEEE. Trans. Nucl. Sci, 44(3), 1464-1468. 